\title{
First occurrence of bean common mosaic virus in soybean [Glycine max] from India
}

\author{
T. K. S. Latha ${ }^{1}$ - V. G. Malathi ${ }^{1}$ • B. D. Haokip ${ }^{1}$ R. Rudhagar ${ }^{2}$ J. R. Kannan Bapu ${ }^{2}$
}

Received: 8 September 2016 / Accepted: 23 January 2017 / Published online: 16 February 2017

(C) Australasian Plant Pathology Society Inc. 2017

\begin{abstract}
The incidence of Bean Common Mosaic Virus (BCMV) in soybean cultivated in western region of Tamil Nadu state, India, was confirmed by symptomatology and reverse transcription-polymerase chain reaction (RT-PCR). Sequence analysis showed nucleotide and amino acid identities of $100 \%$ for the isolate BCMV TN1 with BCMV isolate from China (GenBank Accession No. KJ807806) and the isolates soymosaic2 and soymosaic3 showed highest identity of 98.4\% with the BCMV isolate (GenBank Accession No. KJ807807) in soybean from China. This is the first report on the emergence of BCMV in soybean in India.
\end{abstract}

Keywords Potyvirus $\cdot$ Bean common mosaic virus $\cdot$ RT-PCR

Soybean [Glycine max] otherwise known as 'golden bean' or 'miracle bean', is one of the premier agricultural crops in India. Soybean, with over $40 \%$ proteins and $20 \%$ oil has

\section{T. K. S. Latha}

tkslatha@yahoo.com

V. G. Malathi

vgmalathi@rediffmail.com

B. D. Haokip

betsyhaokip@yahoo.com

R. Sudhagar

genesudha@gmail.com

J. R. Kannan Bapu

kannanbapu@ rediffmail.com

1 Department of Plant Pathology, Tamil Nadu Agricultural University, Coimbatore 641 003, Tamil Nadu, India

2 Department of Pulses, Tamil Nadu Agricultural University, Coimbatore 641 003, Tamil Nadu, India now been recognised all over the world as a potential supplementary source of edible oil and nutritional food. Soybean cultivation has grown rapidly and India is the fifth largest producer in the world accounting for $4 \%$ of total global production. Soybean is known to be infected by several major pathogens and yield loss due to disease, insects and weed species ranges from 20 to $100 \%$ (IPM package for soybean bulletin, 2014). Major viral diseases of national and regional importance are yellow mosaic viruse (genus Begomovirus; family Geminiviridae) and bud blight caused by the species Tobacco streak virus (genus Ilarvirus; family Bromoviridae) (IPM package for soybean bulletin, 2014).

Bean common mosaic virus (BCMV) is a member of the genus Potyvirus belonging to the family Potyviridae. The virus members have monopartite flexuous filamentous particles of about $750 \mathrm{~nm}$ in length encapsidating a positive sense single stranded RNA genome of about $10 \mathrm{~kb}$ size (Bhadramurthy and Bhat 2009). The BCMV is commonly transmitted by inoculation of sap by several aphid species in a non-persistent manner. A high proportion of 3 to $95 \%$ seed and pollen transmission also has been recorded (Zaumeyer and Thomas 1957). In Frenchbean, BCMV produces mosaic and yellow mottling symptoms that appear as a light green-yellow and dark green mosaic pattern on trifoliate leaves. Leaf discoloration is usually accompanied by puckering, blistering, distortion and a downward curling and rolling. The presence of BCMV in India was reported in Vigna unguiculata and Phaseolus vulgaris (Sachchidananda et al. 1973), in Vanilla planifolia (Bhadramurthy and Bhat 2009) and in Lablab purpureus (Udayashankar et al. 2011). Around the world, this virus is known to infect crops such as soybean, mungbean, yambean and many leguminous weed plants.

During the summer season 2014-15, a total of 392 soybean genotypes were screened for incidence of viral diseases at experimental farms of Department of Pulses of Tamil Nadu 




Fig. 1 Symptomatic leaves showing mosaic, leaf distortion and puckering

Agricultural University, Coimbatore, Tamil Nadu, India. Of these, three entries viz., CSB0808, CSB0904 and UGM70 showed mosaic, leaf distortion and puckering symptoms (Fig. 1). The disease incidence in these entries ranged between 23.8 to $37.4 \%$. The symptomatic leaf samples along with nonsymptomatic healthy leaves of those three entries were collected from the field at the flowering stage and the total RNA was extracted using RNeasy Plant Mini Kit (Qiagen, Valencia, CA) and complementary DNA (cDNA) was synthesised (RevertAid $^{\mathrm{TM}}$, Fermentas, India). The polymerase chain reaction was performed using different primer sets of RNA viruses viz., Tospovirus (Li et al. 2011), Tobacco streak virus (Rajamanickam and Karthikeyan 2014), Potyvirus (Hsu et al. 2005) and Tobacco mosaic virus (Letschert et al. 2002). The RNA extracted from the symptomatic leaves of entries CSB0808, CSB0904 and UGM70 yielded an amplicon of the size of $1.1 \mathrm{~kb}$ product with the genus Potyvirus group specific degenerate primer pair PNIbF1/PCPR1 (Hsu et al. 2005) corresponding to the 3 ' end of NIb gene and 5' end of the coat protein gene (Fig. 2). Out of 10 samples tested for each entry, 3 samples were positive by PCR analysis. The RTPCR amplicons were gel purified (GeneJET, Fermentas, India) and each fragment was sequenced bi-directionally (Excelris, Ahmedabad).

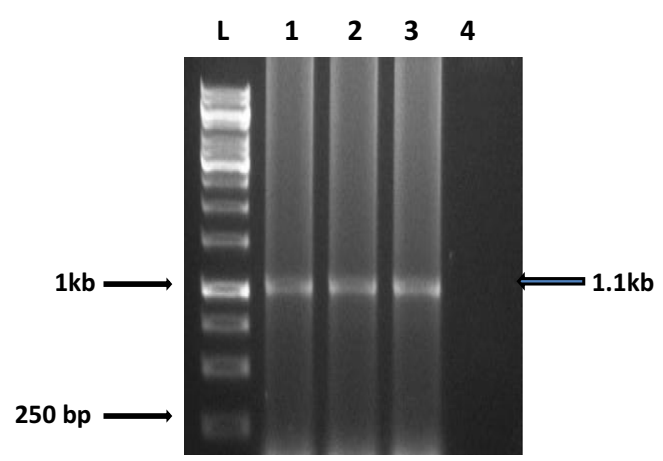

Fig. 2 RT-PCR detection of Potyvirus using degenerate primers, PNIbF1/PCPR1 [L = 1kb ladder, (Genei, Bangalore); Lane1, 2 \& $3=$ template from symptomatic soybean plants; Lane $4=$ template from non-symptomatic soybean plants]

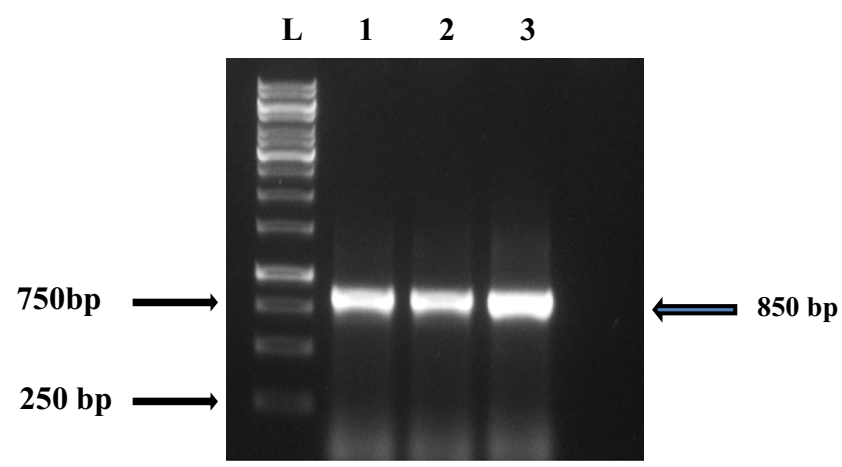

Fig. 3 RT-PCR detection of BCMV using specific primers, AIB90/91 $[\mathrm{L}=1 \mathrm{~kb}$ ladder, (Genei, Bangalore); Lane 1, $2 \& 3=$ template from symptomatic soybean plant; Lane $4=$ template from non-symptomatic soybean plants]

The partial sequences were subjected to NCBI BLAST analysis in which $100 \%$ similarity was observed with the species Bean common mosaic virus; the isolate with which maximum identity observed was from China (GenBank Accession Nos. KJ807806). The cDNA synthesised from the RNA of symptomatic leaves were subjected to RT-PCR using BCMV specific primer AIB90/AIB91 corresponding to 3' end of NIb gene and 3' end of CP gene (Bhadramurthy and Bhat 2009) which yielded a 850 bp product (Fig. 3). All three sequences were submitted in National Centre for Biotechnology Information (NCBI) GenBank (KU213642, KU739386 and KX380786) for the isolates CSB0808, CSB0904 and UGM70 respectively.

The nucleotide sequence of the amplicon BCMV TN1 representing the region from $8323 \mathrm{nt}$ co-ordinate (NIb region) to $9300 \mathrm{nt}$ co-ordinate in the BCMV genome were compared with those of other BCMV isolates in multiple alignment in CLUSTAL-W programme in the Bio-edit software. Within this region compared, BCMV- TN1 isolate from Tamil Nadu exhibited $100 \%$ identity with BCMV isolates from China

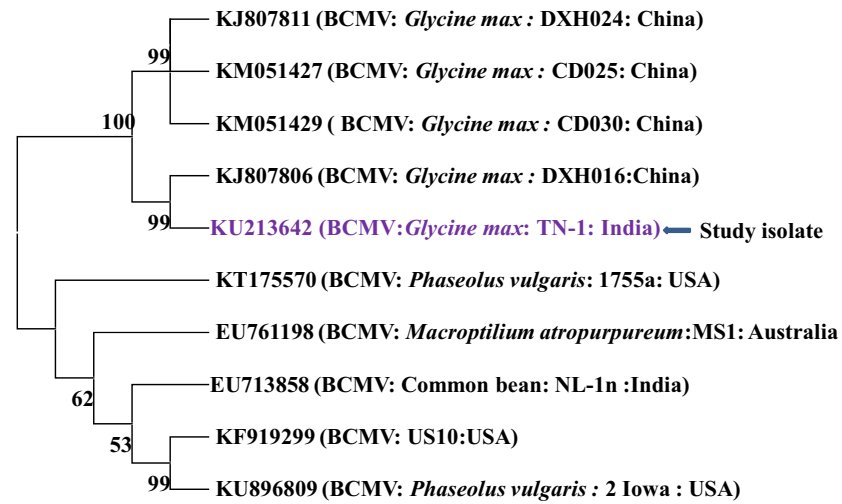

Fig. 4 Phylogenetic dendrogram based on the alignment of partial nucleotide sequence of NIb and coat protein gene of BCMV- TN-1 with that of selected BCMV isolates . Values at nodes represent the percentage bootstrap cores (1000 replicates) only values more than 50 are shown 
Fig. 5 Phylogenetic dendrogram based on the alignment of partial nucleotide sequence of coat protein gene of soymosaic2 and soymosaic3 with that of selected BCMV isolates. Values at nodes represent the percentage bootstrap scores (1000 replicates) only values more than 50 are shown

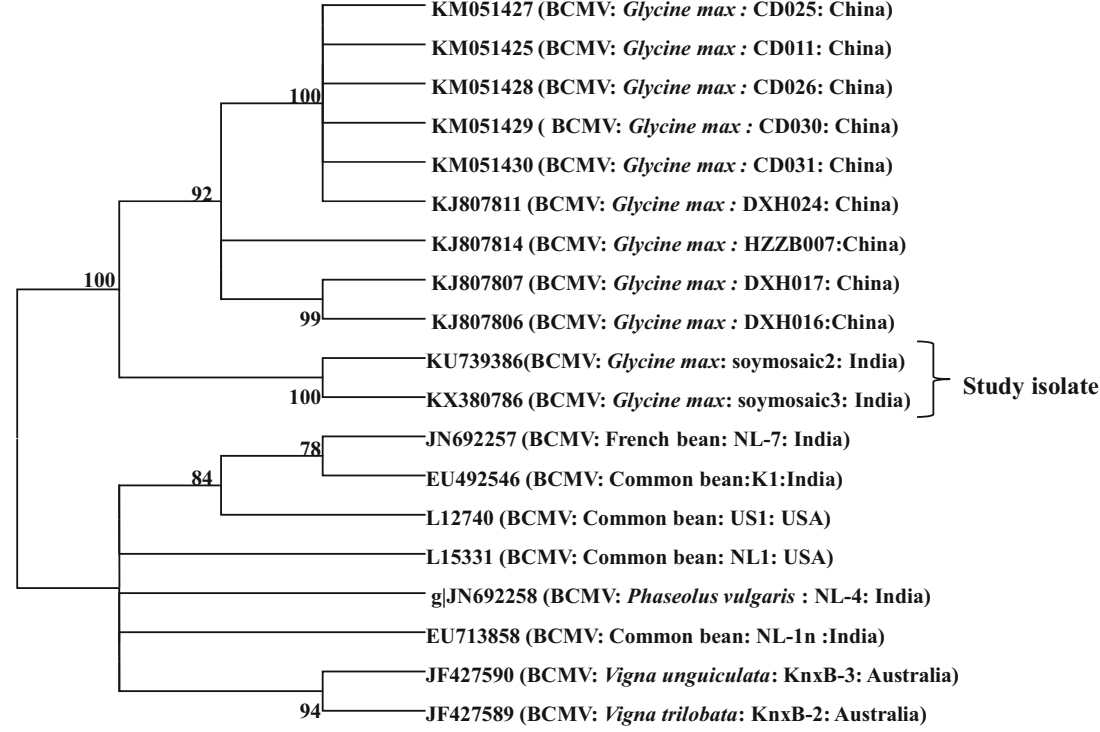

(Accession no. KJ807806). The nucleotide sequence of amplicon from soymosaic 2 and soymosaic 3 isolates representing the region from $8961 \mathrm{nt}$ co-ordinate to $9698 \mathrm{nt}$ co-ordinate were compared with other BCMV isolates. In this region, soymosaic 2 and soymosaic 3 isolates exhibited highest percent identity of $97 \%$ with BCMV isolate from China (Accession no. KJ807807). However, identity with BCMV isolates from Frenchbean and common bean from India was considerably low (90\%).

In the phylogenetic tree comparing the amplicons from 8329 to $9300 \mathrm{nt}$ co-ordinate all the BCMV isolates from soybean clustered together; the TN1 and China isolate KJ807806 occupied a separate branch (Fig. 4). In the phylogenetic tree comparing amplicons from 8961 to 9698, the soymosaic2 and soymosaic3 isolates grouped with all the soybean BCMV isolates form China, well separated from BCMV isolates from Frenchbean and common bean from India (Fig. 5).

BCMV is considered as a pathogen of Frenchbean and cowpea in many countries (Verma and Gupta 2010; Sachchidananda et al. 1973). It has been reported for its presence in crops viz., Vanilla planifolia (Bhadramurthy and Bhat 2009) and lablab (Udayashankar et al. 2011) in India. Zhou et al (2014) and Lee et al (2015) reported the presence of BCMV in soybean from the countries China and South Korea respectively. Until now, BCMV infecting soybean has not been characterised from India. BCMV was associated with the soybean plants showing mosaic mottling symptoms and diagnosis at the right time and destroying the infected plants will eliminate the spread of the disease. This is the first evidence for the BCMV infection in soybean in India.

\section{References}

Bhadramurthy V, Bhat AI (2009) Biological and molecular characterization of bean common mosaic virus associated with vanilla in India. Indian J Virol 20(2):70-77

Hsu YC, Yeh TJ, Chang YC (2005) A new combination of RT-PCR and reverse dot blot hybridization for rapid detection and identification of potyviruses. J Virol Methods 128:54-60

Integrated pest management package for soybean (2014) Technical Bulletin by National Centre for Integrated Pest Management. P.56

Lee LH, Yoon YN, Yun HT, Baek IY, Lim S, Moon JS Lee SH (2015) First report of bean common mosaic virus infecting soybean in South Korea. P1 Dis 99(8):1189

Letschert B, Adam G, Lesemann D, Heinze C (2002) Detection and differentiation of serologically cross-reacting tobamoviruses of economical importance by RT-PCR and RT-PCR RFLP. J Virol Methods 106(1):1-10

Li JT, Yeh YC, Yeh SD, Raja JAJ, Rajagopalan PA, Liu LY, Chen TC (2011) Complete genomic sequence of Watermelon bud necrosis virus. Arch Virol 156:359-362

Rajamanickam S, Karthikeyan G (2014) Sequence diversity analysis of Tobacco streak virus infecting okra (Abelmoschus esculentus) in India. J Pure Appl Microbiol 8(6):4759-4767

Sachchidananda J, Shamsher S, Prakash N, Verma VS (1973) Bean common mosaic virus on cowpea in India. J P1 Dis Protec 80:88-91

Udayashankar AC, Chandra NS, Niranjana SR (2011) First Report of Bean common mosaic virus infecting Lablab purpureus in India. Plant Dis 95:881

Verma P, Gupta UP (2010) Immunological detection of Bean common mosaic virus in French bean (Phaseolus vulgaris L.) leaves. Indian J Microbiol 50:263-265

Zaumeyer WJ, Thomas HR (1957) A monographic study of bean diseases and methods for their control. USDA tech. Bulletin 868:255

Zhou GC, Wu XY, Zhang YM, Wu P, Wu WZ, Liu LW, Wang Q, Hang YY, Yang JY, SHao ZQ, Wang B, Chen JQ (2014) A genomic survey of thirty soybean infecting bean common mosaic virus (BCMV) isolates from China pointed BCMV as a potential threat to soybean production. Virus Res 191:125-133 